\title{
Isaac LEVI, Pragmatism and Inquiry: Selected Essays
}

Oxford, Oxford University Press, 2012

Gabriele Gava

\section{(2) OpenEdition}

1 Journals

Electronic version

URL: http://journals.openedition.org/ejpap/521

DOI: 10.4000/ejpap.521

ISSN: 2036-4091

\section{Publisher}

Associazione Pragma

\section{Electronic reference}

Gabriele Gava, «Isaac LEvı, Pragmatism and Inquiry: Selected Essays », European Journal of Pragmatism and American Philosophy [Online], VI-1 | 2014, Online since 08 July 2014, connection on 23 September 2020. URL : http://journals.openedition.org/ejpap/521 ; DOI : https://doi.org/10.4000/ejpap.521

This text was automatically generated on 23 September 2020.

\section{(c) $($ ) $(3)$}

Author retains copyright and grants the European Journal of Pragmatism and American Philosophy right of first publication with the work simultaneously licensed under a Creative Commons AttributionNonCommercial-NoDerivatives 4.0 International License. 


\title{
Isaac LEVI, Pragmatism and Inquiry: Selected Essays
}

Oxford, Oxford University Press, 2012

\author{
Gabriele Gava
}

\section{REFERENCES}

Isaac Levi, Pragmatism and Inquiry: Selected Essays, Oxford, Oxford University Press, 2012.

1 Isaac Levi is a central figure in contemporary pragmatism, who, drawing extensively on the philosophy of classical pragmatists like Charles S. Peirce and John Dewey, has been able to successfully develop, correct, and implement their views, thus presenting an innovative and significant approach to various issues in contemporary philosophy, including problems in logic, epistemology, decision theory, etc. His books (just to mention a few of them) Gambling with Truth (Knopf 1967), The Enterprise of Knowledge (MIT Press 1980), Hard Choices (Cambridge University Press 1986), and The Fixation of Belief and Its Undoing (Cambridge University Press 1991) propose a solid and elaborate framework to address various issues in epistemology from an original pragmatist perspective. The essays contained in Pragmatism and Inquiry investigate ideas that constitute the core of Levi's philosophy (like corrigibilism, his account of inquiry, his distinction between commitment and performance, his account of statistical reasoning, his understanding of credal probabilities, etc.), but they do so by putting these views in dialogue with other important philosophical figures of the last and present century (like Edward Craig, Donald Davidson, Jaakko Hintikka, Frank Ramsey, Richard Rorty, Michael Williams, Timothy Williamson, Crispin Wright, etc.), thus providing a renewed entry-point in his thought. The collection contains 11 essays which have been all published already. It is good to have these articles collected together, because they are very interrelated and they present a systematic view. However, it would have been useful to have a longer introduction (the one in the book is just 3 pages long), which 
guided the reader among the conceptual relationships between the chapters, and which identified their relevance in the current philosophical context.

Insofar as there is much interrelation and overlap among the articles, I will avoid commenting them singularly one after another. I will rather identify some of the central themes that run through the book and point out where relevant ideas about these themes are presented in the collection. The first topic I wish to focus on is Levi's original account of the tasks and purposes of epistemology. According to Levi, epistemology should not be understood as a discipline that identifies the principles according to which we can decide whether our beliefs are justified or not. He takes from the classical pragmatist (in particular from Peirce and Dewey) what he calls the principle of doxastic inertia, or doxastic infallibilism (cf. 32, 231), according to which we have no reason to justify the beliefs we are actually certain of. The task of epistemology is thus not that of justifying our current beliefs, but rather that of justifying changes in beliefs (cf. 165-71). In this context, Levi develops an interesting and original perspective which associates infallibilism and corrigibilism. We should be infallibilist about the beliefs we currently hold as true (according to Levi, it would be incoherent to hold them to be true and stress that they could be false as fallibilists do). Nonetheless we can be corrigibilist about our beliefs, because we can held them to be vulnerable to modification in the course of inquiry. ${ }^{1}$ This means that we cannot but regard our current beliefs as true, even though we can consider them as open to correction in the course of future inquiry (cf. 120). At this point, it is interesting to refer to Levi's discussion of the claim, advanced for example by Rorty, that we should aim at warranted assertibility and not at truth. According to Levi, this claim could be understood in different ways. On the one hand, it could be read as implying that we should increase the number of beliefs that are acquired through well-conducted inquiry (133). This would be contrary to the principle of doxastic inertia proposed by the classical pragmatism, because we would require a justification for beliefs we already had. Consequently, if we read Rorty's claim in this way, his pragmatism would abandon one of the central views of this very tradition. On the other hand, if warranted assertibility is understood as a specific aim of inquiries we actually pursue (where we thus need a justification because we are trying to introduce changes in our beliefs), the simple contention that we should aim at warranted assertibility remains empty if we do not specify which are the proximate aims of the inquiry in question (and if we do so, it seems that a central aim of at least some inquiries should be the attainment of new error free information: a goal that Rorty would probably reject as an aim of inquiry) (cf. 130, 133).

3 From this account of the role and purposes of epistemology, it is clear how the analysis of the structure and procedures of inquiry plays an essential role in Levi's theory of knowledge. This is the second topic I wish to address. Levi often recognizes his debt to Peirce and Dewey in his account of inquiry (cf. 1), but he also insists that we should develop their views further in order to attain a consistent position. He agrees with Peirce that inquiry is the process which allows us to pass from a state of doubt to a state of belief (cf. 83), but, following Dewey, he criticizes Peirce's psychological description of these states (1-2). ${ }^{2}$ However, he does not endorse Dewey's strategy to avoid psychologism, that is, his description of inquiry as a process starting with an indeterminate situation and ending with a determinate situation $(2,84-5)$. Rather, he understands changes in states of belief as changes in doxastic commitments, where states 
of belief understood as commitments are to be distinguished from states of belief understood as performances. Accordingly, a doxastic commitment identifies the set of beliefs we commit ourselves in a state of full belief. It could be totally different from the views we consciously endorse, which identify our state of doxastic performance (cf. 106). A state of belief understood as commitment has then a normative component, because it describes what we should believe and not what we actually believe. Besides identifying the beliefs we are committed to endorse, our state of full belief also decides which are the possible views and theories, on which we might rationally have doubts about (48). In other words, a state of full belief (understood as commitment) decides the space of serious possibilities we can rationally inquire about (169). Accordingly, inquiry should not be understood as a process that generates changes in doxastic performances (which would concern our psychological dispositions and states), but rather as a process which results in changes in doxastic commitments (108).

Changes in doxastic commitments can concern either the extension or contraction of our state of full belief. Levi offers us a detailed analysis of the ways in which these changes can be justified.

5 Extension can be justified by either routine expansion or deliberate expansion, where routine expansion identifies a "program for utilizing inputs to form new full beliefs to be added to X's state of full belief K" (235). Levi refers here to a "program" because he wants to distinguish this kind of expansion from a conclusion obtained through inference, where, for example, the data would figure as premises of an induction (236). The difference here is that the "program" tells us how to use the data before the data are collected, whereas in inductive inferences there is no such identification in advance. He reads Peirce's late account of induction as developing some elements along these lines (72-3) and he finds some affinities with Hintikka's account of induction as a process "allowing nature to answer a question put to it by the inquirer" (204).

6 Our state of full belief can also expand by means of deliberate expansion. In the latter "the answer chosen is justified by showing it is the best option among those available given the cognitive goals of the agent" (236). "The justified change is the one that is best among the available options (relevant alternatives) according to the goal of seeking new error-free and valuable information" (237). However, when we expand our state of full belief we can inadvertently generate inconsistencies among our beliefs. When we are in this inconsistent state of belief, we cannot but give up some of our beliefs in order to avoid contradictions. In contracting our state of full belief, we have basically three options. We can give up the new belief that generated the inconsistency or we can give up the old belief with which it is in contradiction. Alternatively, we can also suspend judgment between the two. In all these cases we have a contraction of the state of full belief. Levi describes the criterion which should be followed in deciding between these three options as follows: "In contracting a state of belief by giving up information $\mathrm{X}$ would prefer, everything else being equal, to minimize the value of loss of the information X is going to incur" (230). In deciding weather to give up either the new or the old belief, $X$ should then take into consideration which retreat would cause the smaller loss of information. If the loss of information would be equal in the two cases, then X should suspend judgment about the two (181, 229-30). This account of inquiry and of the way in which it justifies changes in doxastic commitments is part of an elaborate and original approach to epistemology. It draws its basic insights from 
Peirce's and Dewey's account of inquiry, but it develops their views in an extremely original and detailed view, which constitutes the core of Levi's philosophy.

Levi's book contains also interesting reflections on the concept of truth. He argues that, from a pragmatist point of view, we should not be interested in giving a definition of this concept, which clarifies what we do when we use the predicate "is true" in sentences and propositions. Rather, we should be interested in how the concept of truth is relevant for understanding the way in which we change beliefs through inquiry (124-5). Levi criticizes those accounts of inquiry which claim that inquiry should not aim at truth but at warranted assertibility (e.g. Rorty, Davidson, sometimes Dewey) (ch. 7). Against these views, he maintains that a concern with truth is essential to understand at least some of our inquiries, that is, those inquiries which aim to justify changes in full beliefs. It seems essential that these inquiries should try to avoid error (an aim that should be associated with the purpose of attaining new information) and this seems to have an indirect connection with the aim of finding out the truth (135-6). On the other hand, Levi rejects Peirce's account of truth as the final opinion that we will reach at the end of inquiry. According to Levi, proposing this understanding of truth as the aim of inquiry would result in insoluble inconsistencies with the kind of corrigibilism that Levi endorses and that he also attributes to Peirce (138-40). Levi's view seems to be the following: if in my current state of belief I believe $h$ is absolutely true, then I should regard it as an essential part of the final opinion I aim to reach "in the long run." Thus, I should not be prepared to give up $h$ (which would contradict Peirce's corrigibilism), insofar as at further steps in inquiry I could end up believing the contrary view (which I now believe is false). Levi concludes that at any determinate time in inquiry we should not be concerned with making the best move in order to contribute to the attainment of the truth intended as the final and definitive description of the world. On the contrary, we should just try to obtain new error-free information in the next proximate step of inquiry. I do not think that this way of presenting Peirce's views is fair to his actual position, for two main reasons: (1) Peirce's account of truth as the final opinion can be read as identifying not substantial theses about reality or the ultimate aims of inquiry, but the commitments we make with respect to a proposition when we asserts that it is true: that is, we commit ourselves to the view that it will hold in the long run; ${ }^{3}$ (2) even if we identify the attainment of truth as the ultimate aim of inquiry, it seems possible, within Peirce's model, to maintain that we can be corrigibilist about the views we currently consider true. Of course it would be irrational to doubt or give up these views as long as we still believe in them (this is basically what Levi calls Peirce's principle of doxastic inertia). This does not imply that we cannot consider those views as corrigible, given that we could incur in circumstances (like new evidence gained through experience, or the identification of inconsistencies in our set of beliefs, etc.) that justify the emergence of a doubt on those views. If we were in these circumstances, it would not be problematic to give up those views, insofar as we would not be any more completely certain that they are true. If our aim were thus the attainment of truth in the long run, we would be justified to give up those views insofar as we would not be any more certain that they contribute to the attainment of the final opinion.

8 Levi's book also contains important scholarly contributions on Peirce and Dewey. It is undeniable that his approach to the writings of both Peirce and Dewey is strongly influenced by his own views and interests, but Levi is surely distinctive among the central figures in contemporary pragmatism for reading these classics with the 
attention they deserve. Chapter 4 "Beware of Syllogism: Statistical Reasoning and Conjecturing According to Peirce" presents a reconstruction of the evolution of Peirce's account of induction and hypothesis. Levi shows how Peirce later abandons his early attempts to define these kinds of inferences by means of a permutation of the structure of a categorical syllogism. In his later writings Peirce first begins to regard these inferences as permutations of statistical deductions (75), and he then abandons this strategy in favor of a description of deduction, induction and abduction reflecting their roles in inquiry (77-8). Chapters 5 "Dewey's Logic of Inquiry" and 6 "Wayward Naturalism: Saving Dewey from Himself" contain interesting considerations on Dewey's theory of inquiry and the kind of naturalism we should associate with it. Insofar as the two articles overlap in many respect (unfortunately sometimes the overlap is not only relative to the topics, but textual!, which makes one wonder if it would not have been better to include only one of the two in the collection) I will discuss them together. With respect to chapter 4 on Peirce, these articles are less scholarly and more concerned with a correction of Dewey's views along the lines Levi suggests. In these chapters, Levi discusses a multiplicity of issues, but I will limit myself to the consideration of his criticism of Dewey's naturalism (cf. 85-8, 111-16). Accordingly, Levi claims that "activities like believing, evaluating, inquiring, deliberating, and deciding are resistant to naturalization" (105), if the latter is understood as an explanation of these activities by means of psychological or behavioral dispositions. In his attempt to show continuities between the way in which humans rationally conduct inquiries and the way in which animals respond to the challenges posed by their environment, Dewey commits exactly this naturalistic fallacy (cf. 85, 111). However, states of full belief, understood as doxastic commitments, involve a normative element that cannot be reduced to dispositions (106). Endorsing an approach to inquiry based on commitments is equal to endorsing a better naturalism, which Levy calls wayward naturalism (cf. 103-4), and which does not substitute old supernatural entities with new ones (according to Levi, the appeal to dispositions as universal means of explanation in epistemology introduce a new kind of supernaturalism). Following Levi, if we read Dewey properly, it becomes evident that we cannot but develop his account of inquiry in this way (108-9).

9 To conclude, it is surely good to have these essays collected together, insofar as they offer a new perspective on some of the central insights of Levi's philosophy thanks to a fruitful discussion with recent developments in epistemology. Even though sometimes the overlap between the articles is so significant (as in the case of chapter 5 and 6), that it would have been advisable to avoid redundancies, the texts here presented are surely of interest for any scholar who believes that the classical pragmatists' account of inquiry has still a lot to offer to the current philosophical debate.

\section{NOTES}

1. However, one might argue that this is exactly what many fallibilists contend, but this would just be a matter of definition. 
2. Peirce himself later criticizes the psychological account of the principles of inquiry that he gave in "The Fixation of Belief."

3. On this reading of Peirce's account of truth see: C. Hookway, The Pragmatic Maxim, Oxford, Oxford University Press, 2012, 69.

\section{AUTHORS}

\section{GABRIELE GAVA}

Goethe-Universität Frankfurt am Main, Deutschland gabriele.gava[at]gmail.com 